\title{
ON THE DIAGNOSIS AND TREATMENT OF THE DISEASES OF THE FRONTAL SINUS.*
}

BY I.EWIS A, COFFIN, M.D., NIEW YORK.

Were our knowledge of the discased frontal sinus and the desired results of our treatment of that sinus commensurate with the amount of literature on the subject, we might better occupy our time in the consideration of other stubjects to-day; but all feel, probably, that we have not as yet attained the best to be hoped for in the treatment of frontal sinus disenses. Nevertheless, the fact that so much is now being written, and that by so many different. workers, each of whom must feel that he has some mite which he would add to the already known and tried, is a sure sign of progress and gives promise of better knowledge and results.

It may be taken for granted probably that all know where the frontal sinus is, its anatomy, how drained, its relation to the other sinuses, etc. Of its functions I have never seen one mentioned that impressed me more than to make me feel that inasmuch as it probably has a function, this may be it, but I clon't think so. Various operations have been proposed and clone, and $\mathrm{I}$ am sure the names of Ogston, Luc, Jansen, Kuhnt, Czerny and Golovine, present to the mind of any rhinologist a more vivid picture of the classical. operations done and described by these men than any description which I might make, could possibly do.

I shall content myself, therefore, with a discussion of the diagnosis, the various operations and the statement of deductions from my personal observation and experience.

\section{DIAGNOSIS: I. ACU'TE.}

The diagnosis of acute sinusitis presenting its full quota of recognized symptoms, offers but little trouble to the trained rhinologist or surgeon. A case which comes before us suffering acutely from frontal headache extending outward toward the temple, giving history of a lately preceding attack of acute rhinitis, grippe, measles, typhoid, syphilis, or other malady, often attended by disordered function of the respiratory mucosa, and complaining

* Read before the lighth Aunual Meeting of the American Laryngological, Rhinological and Otological Society, Washington, D. C., June and to 4 th, 1902. 
of an increased nasal discharge from the affected side, presents the subjective side of the picture, and directs our attention to, as well as our efforts toward the exploration of the frontal cavity. If our suspicions are right, we shall find probably, extreme tenderness over the supra-orbital ridge and along the orbital roof, with a possible bulging over the affected sinus or into the orbit. On intra-11asal inspection the mucous membrane is seen to be swollen and boggy, and pus will probably be found in the middle and inferior turbinals, the pus may have been forced up over the anterior end of the middle turbinated, and be seen coming down between that bone and the septum as though from the posterior ethmoidal cells or sphenoidal sinus.

Let me emphasize this point. In empyema of the frontal sinus or anterior ethmoidal cells, if consiclerable pressure exists between the swollen middle and inferior turbinals, pus may be seen coming down between the middle turbinated and septum. This, of course, is not mentioned as a diagnostic sign of disease of the frontal sinus or anterior ethmoidal cells, but if pus be scen in the lower part of the superior meatus, it need not necessarily mean disease of the posterior ethmoidal cells or sphenoidal sinus. Removal of the anterior tip of the middle turbinal will settle the matter.

Adding to the subjective side of the picture these objective signs, we have a fairly certain knowledge that disease of the frontal sinus exists. I believe that in all such cases barring anatomical anomalies that our trans-illumination lamp will confirm and make certain our cliagnosis. The $x-r a y$ is said to be a valuable diagnostic agent, but I have had no experience with its use.

\section{CHRONIC.}

The diagnosis of a chronic empyema may not be so easy. Many cases have their origin by the extension of a chronic process from the nasal cavities, in which case if good drainage persists, I believe that the condition may exist for years and never be discovered except for the aroused suspicions of the rhinologist conn. sulted for the relief of the catarrhal condition of the nose. There is little or no pain on pressure; may be no, or only occasional pain, and trans-illumination may in such cases be of little use, and resort must be had to opening of the sinus either intra-nasally or externally. Those chronic cases in which the mucous membrane has taken on an unhealthy granulation or from which polypi have 
developed, present all the symptoms due to pressure from a filled up sinus, which have been described as the symptoms of an acute sinusitis, and the cliagnosis of the chronicity must be made from the history of the case considered in connection with the appearance and condition of the intra-nasal structures.

The frontal sinus is the fairly frequent site of osteomata and may contain angiomata. For the diagnosis of these conditions we must rely upon the subjective symptoms and trans-illumination and the $x$-ray for a working basis, and the sinus must be exr amined by an exploratory opening for a certain diagnosis. This, the writer claims, is not only a justifiable procedure, but a positive cluty in any suspected case, and further claims that if done under proper aseptic methods by making an osteoplastic operation, if merely, for exploration, the patient need hardly lose a day from his ordinary life, and that in the course of ten clays to two weeks no trace will remain to show that the sinus was ever opened.

Having seen so many cases in my clinic at the Manhattan Eye and Ear Hospital which left in the minds of the entire staff a doubt as to whether the sinus was diseased or not, many of whom were allowed to drift along under a temporizing form of treatment to eventually have a sinus opened to be found in a diseased condition -has led the writer to have constructed a trephine by means of which any part of a circle may be cut. (See cut.) By use of this instrument it is possible, having dissected up the soft tissues from the periostcum, to easily make an osteoplastic flap. In case no disease be found, the hinged button may be replaced and the soft tissues sutured. Primary'union taking place, no facial deformity exists. The incision both in the soft tissues and bone is quite similar to that clescribed by Golovine, although the instrument was devised and used previous to reading his article. It is new.

We have opened but one healthy sinus which was done about six weeks ago, and it is impossible to tell by sight or touch, the location of the opening. In case disease be found, we must decicle whether to operate further and what operation shall be clone. As to whether we shall operate further in the effort to effect a cure, in a great majority of cases I would answer yes. Of those cases presenting pressure symptoms there can be no question. In many of the chronic cases, complaining of no symptom except the more or less troublesome discharge from the nose, it is at the best a choice of evils, and must be left largely to the decision of 
the patient. I should feel that inasmuch as it was seeking relief that placed the patient in our hands, that we are at least justified in doing such operation as we feel will remedy the evil.

\section{AS TO WHAT OPERATION SHALL BE DONE.}

- Dr. Richards in his excellent paper read before his Society at its last meeting, justly criticises the calling of the various operations after their real or fancied originators, and suggests describ. ing them rather according to their anatomical characteristics. I would suggest as an alternate proposition, naming or describing them according as they vary in principle. For example, I would put them all into either of two classes according as the external wound is immediately closed or kept open and treated as an open wound, speaking of them for convenience, as the open or closed method.

In the closed method the intra-nasal drainage tube is a necessity; while in the open method it may or may not be used, influencing the results not in the least or to a very limited clegree, and adding much discomfort to the patient. Undoubtedly both methods have effected cures and the fecling of the writer is that each has its place, and should be used according to conditions found on exploratory examination.

For example, if on examination there be found a simple cmpyema without destruction of mucus lining, the symptoms due to an occluded fronto-nasal passage, I think one would be justified in closing the external wound immediately, having established drainage into the nose. If a tube is to be used, a soft rubber tube drawn down through the nasal duct offers the best chances of success. Drainage thus established and the sinus washed out from time to time, a cure should result in a comparative short time with little or no facial deformity. I feel that the soft rtbber drainage tube drawn down as nearly as possible through the natural frontonasal duct offers better promise of success for these reasons :-

First. Little violence is done to the mucous membrane of duct, and it will not subsequently fill with granulations.

Second. The natual canal is tortuous, opening backward into infundibulum, and if kept intact will offer greater protection against future infection than would be offered if a successful attempt be made to establish an artificial duct opening downward and forward through which a metal or hard rubber tube has been inserted.

Third. An artificial canal is very liable, if not sure, to become 
obliterated by grantulation. This conclusion is altogether at variance with conclusions drawn by Dr. Richards, but is drawn entirely from personal observation. The worst result I ever saw was in a case operated by a skilled general surgeon having had large experience in our special field. The whole anterior ethmoidal region was curetted out, making the largest fronto-nasal opening I have ever seen, and a large drainage tube put in place. Everything for a time went well and the patient was discharged, while in the minds of the surgeon associates were admiration and envy of his daring and skill, but the case soon returned with a large fluctuating mass over the eye, and the operation was repeated on the same lines, to recur again, until finally a complete cure was effected with so great a facial deformity as to make it impossible for the man since to obtain employment. This surgeon, I am sure, has effected several very satisfactory cures since, but has become converted to the open method. The literature of frontal sinus treatment by the closed method is replete with these relapses.

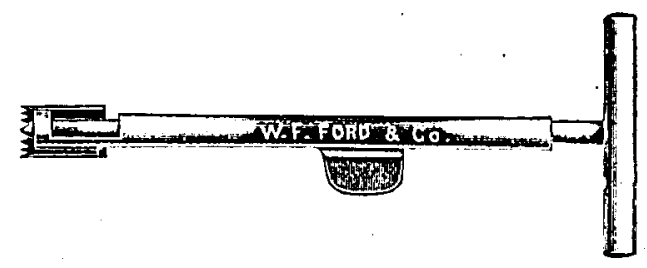

Author's 'Trephine.

In all cases where great destruction of the mucosa has taken place with attendant bone necrosis, or where a great amount of unhealthy granulation has taken place, or where polypi have formed, or where osteomata or angiomata exist; in fact, in any case where extensive curettement must be practiced, whether limited to the sinus or ethmoidal cells, I believe that the open method should be practiced in the effort to obliterate the sinus. In all such cases I think the only rule necessary as to size of opening is that it should be sufficiently large so that all parts of the sinus may be satisfactorily cxamined and treated, and no larger.

The point of opening is of importance. For exploratory purposes, the author would suggest that it be as near as possible to the median line, using the trephine in such manner as that the hinge of the osteoplastic flap shall be.toward the external canthus of the eye, the lower erlge of the trephine cutting just sufficiently low to take in the lowest part of the anterior.wall. If it be neces- 
sary to enlarge this, it should be first enlarged at the expense of the inferior wall toward the nose. If a greater opening than can thus be made, be necessary, it can be carried outward just along the supra-orbital ridge at the expense of both the lower borcler of the lower wall, until the entire cavity can be examined and treated.

Of several cases, five in all, so treated at the Manhattan Eye \& Ear Hospital, hone have failed of a speedy cure, and no relapses. The time of treatment has varied from three to six weeks. In no case has there been enough deformity to bring forth the least complaint of patient, and in two at least, close inspection is necessary to see that any operation has been made.

While on this point, I wish briefly to refer to one case under care of Dr. T. J. Harris :

The patient, a young woman twenty-eight years, on whom Dr. Harris performed the regular Luc operation, removing a small amount of the anterior wall, inserting a drainage tube into the nose. External wound closed. Discharged, curecl, relapsed. Sinus reopened and treated as open wound. Time elapsing between original operation and cure, one year, with considerable deformity due to marked depression at point of bone destruction. Six weeks ago reopened because of persistent nasal discharge and for cosmetic effects, opening through bone enlarged at expense particularly of the inferior wall toward the nose; treated by open method with drainage into nose. At this time the sinus is nearly obliterated, external wound nearly closed and marked improvement as to cosmetic results.

I mention this case simply to show that it is not the amount of bony wall removed so much as what part is removed, that influences the cosmetic effects.

Of intra-nasal operation, beyond removal of the anterior end of the middle turbinated and the breaking down of the anterior ethmoiclal cells, I have nothing to say but to condenn. Many cases may be relieved, and possibly cured, by this simple procedure, followed by such washing of the sinus as we are able to do, but all cases failing of cure by such means, and clemanding for any reason that a cure be made, should unhesitatingly be opened and subjected to such treatment as seems best suited to the case.

To recapitulate:

I trust you will pardon me if I sum up the points to which I wish to invite your attention in a dogmatic manner. 
First. Exploratory incision by osteoplastic flap should be done on all cloubtful cases and in all cases presenting symptoms which could be accounted for by a diseased frontal sinus where ordinary medical or more simple surgical means have failed to give relief; intra-nasal symptoms may be wanting.

Second. Exploratory opening should be as low as possible in the anterior wall and just over the inner canthus of the eye. If necessary to sacrifice the bony flap, the opening should be enlarged at expense of the inferior wall, and if greater opening be necessary, it should be done at expense of both the anterior and lower walls.

Third. Every part of sinus should be explored and treated according to conditions found.

Fourth. No more work should be done between the sinus and nasal cavity than is necessary to remove the cliseased portion of the parts in that location.

Fifth. The closed method should be used only in such cases as are due to obstructed fronto-nasal ducts without extensive disease of mucous lining of sinus, and in which the obstruction can be removed without great violence to the natural fronto-nasal duct.

Sixth. The open method is the surer method in all cases, and the only method in cases of much cliseased mucous lining or bony wall or extensive ethmoiditis, making necessary considerable curettement of both sinus and ethmoidal region or either of them, as well as in cases of adventitious growths in the sinus, the author believing that inasmuch as the obliteration of the sinus is the desired end, there is no more need of artificial drainage into the nose than there is that we make artificial drainage into the middle ear when we attempt to obliterate the mastoid antrum and cells.

Seventh. The so-called intra-nasal operation of boring or drilling jnto the frontal sinus while it may relieve symptoms, is noncurative, uncertain and clangerous, and should be condemned. 